DOI: http://dx.doi.org/10.17793/rdd.v4i6.632

\title{
5. O QUE OCORRE APÓS O ESTABELECIMENTO DE UMA PAZ PERPÉTUA? UM OLHAR SOBRE O ADMIRÁVEL MUNDO NOVO DE ALDOUS HUXLEY
}

\author{
5. WHAT HAPPENS AFTER THE ESTABLISHMENT OF A PERPETUAL PEACE? A \\ LOOK ON THE BRAVE NEW WORLD THROUGHT ALDOUS HUXLEY
}

\author{
Kelly Lissandra Bruch ${ }^{1}$ \\ "Pois paz sem voz, paz sem voz \\ Não é paz, é medo!" \\ Marcelo Yuka - O Rappa
}

\begin{abstract}
Resumo:
Entre uma vida estável, vigiada, sem liberdades e sem vontades, e um estado de permanente guerra, pelo que optar? Há como optar? O presente artigo tem como objetivo traçar um paralelo entre o Admirável Mundo Novo, apresentado na obra de Aldous Huxley, e o estabelecimento de uma possível paz perpétua segundo a lógica preconizada por Kant. Além disso, localiza a obra desse primeiro no contexto em que ela foi escrita - entre as duas Grandes Guerras - e as inspirações que até hoje a mesma traz, seja para o cinema, para a literatura, para a música, seja para a própria realidade. Como resultados, conclui-se a necessidade de se revisitar clássicos da literatura como o ora discutido, para que se repense e se rediscuta a atualidade. Verifica-se quanto de concreto pode haver em uma ficção, que expõe aquilo que se teme dizer, por vezes, em relação à realidade. A autora não acredita em uma paz perpétua, mas em uma evolução e revolução constante da humanidade, que implica na existência e na conservação de um direito pleno à liberdade.
\end{abstract}

Palavras-chave: paz perpétua, estabilidade, guerra.

\begin{abstract}
:
Between a stable live, monitored, without freedom and without wills, and a state of permanent war, what to choose? Anyone have a choice? This article aims to draw a parallel between the Brave New World, presented at Aldous Huxley's book, and the establishment of Perpetual Peace, according to Kant's logic. Moreover, it locates the Aldous Huxley's work in the context in which it was written - between the two Great Wars - and the inspirations that today this brings for films, books, music, and the reality itself. As a result, on can see there is a need to revisit the classics of literature as discussed herein, for a rethinking and review the present. It appears as concrete can be the fiction, that exposes what is feared to say, sometimes in relation to reality. The author does not believe in a Perpetual Peace, but in a constant evolution and revolution of humanity, which implies the existence and maintenance of a permanent right to freedom.
\end{abstract}

Keywords: perpetual peace, stability, war.

\footnotetext{
${ }^{1}$ Doutora em Direito pela Université Rennes I, France em co-tutela com a UFRGS. É como consultora jurídica do Instituto Brasileiro do Vinho IBRAVIN desde 2005, consultora técnica do Instituto Rio Grandense do Arroz IRGA desde 2010, professora da CESUCA e da Faculdade Iguaçu, professora do MBA em Gestão e Comercialização para a Cadeia do Arroz do I-UMA, professora colaboradora no Programa de Mestrado Profissional em Biotecnologia e Gestão Vitivinícola da UCS. E-mail: kellybruch@gmail.com
} 


\section{Introdução}

Toda vez que se termina uma grande guerra, que todos estão cansados, desgastados pelas dores das muitas perdas, sonha-se com a paz; mas uma paz perpétua, uma paz eterna, um mecanismo, um contrato, um meio de garantir que esta carnificina não retorne, que o pesadelo nunca mais volte, e que se vire a página da realidade. Todavia, parece que as guerras têm feito parte das vidas dos homens desde antes de se ter cunhado o termo humanidade, a tal ponto que até à guerra se estendeu a regulação das relações sociais, conforme comprova Alberico Gentili ao escrever de Iure Belli Libri Tres, que para o português foi traduzido como O Direito da Guerra (2005), visando regular o que seria uma guerra justa.

O admirável mundo novo que Huxley (2009) apresenta, é um mundo que sobrevive a uma destas guerras, que quase leva ao fim da humanidade e também leva alguns homens a decidirem que não haverá mais guerras. Mas como?

\section{1 - Haveria como se garantir uma Paz Perpétua?}

Em seu esboço filosófico para a Paz Perpétua, Kant (2004) buscou, ainda no século XVIII, sugerir um estatuto para o estabelecimento da paz perpétua entre os Estados. Claro que era uma paz com base em princípios eurocêntricos, embora disfarçados de cosmopolitas (DERRIDA, 2004), posto que o cosmos, mesmo que reduzido ao Planeta Terra, precisaria considerar a diversidade de origens, de línguas, de formas de pensar, dando a estes igual estatura para a construção de princípios para uma paz terrestre, ao mesmo tempo que deveria permitir a estes a liberdade de olhar o outro e conviver com o outro, sem que nenhum fosse considerado errado, inadequado, selvagem, atrasado, pouco evoluído, inaplicável, etc. Mas como olhar para o outro e reconhecer-se no outro? Como praticar esta alteridade?

Quando o Dr. Bernard Marx leva Lenina para a Reserva, e quando estes se deparam com os selvagens, eles não veem nem se reconhecem nestes. Eram mundos tão distantes em que viviam Bernard e John - o selvagem - que o primeiro chega a exclamar: 
[...] - Pra mim é tão difícil de compreender, de reconstruir - dizia Bernard - Como se vivêssemos em planetas diferentes, em séculos diferentes. Uma mãe, e toda essa sujeira, e os deuses, a velhice, a doença .... - Balançou a cabeça - É quase inconcebível. Nunca chegarei a compreender, a menos que você me explique (HUXLEY, 2009, p. 195).

Mas há momentos nos quais nem explicar, nem detalhar, nem desenhar consegue transmitir o que é o outro, compreender o que é o outro, colocar-se no lugar do outro.

Vasculhando um pouco mais a história, encontram-se dois eventos denominados de Primeira Guerra Mundial e Segunda Guerra Mundial².

Entre estes dois eventos, após a também denominada Grande Guerra, uma das sugestões de Kant (2004) foi acatada: cria-se a Liga das Nações, com o objetivo de buscar manter a paz após o que foi considerada uma das mais sangrentas batalhas de todos os tempos. Claro que apenas algumas das sugestões foram acatadas, pois o primeiro aviso de Kant é que "não deve ser considerado válido nenhum Tratado de Paz que possa ser convertido, com uma ressalva secreta, na matéria de uma Futura Guerra."(2004, p. 32) O Tratado de Versalhes, de 1919, embora tenha sido denominado Tratado de Paz e criado a denominada "Liga das Nações", com dois objetivos: manter a ordem e evitar a guerra (WATSON, 2004); tem em seu escopo ainda a beligerância, posto que declara vencedores e perdedores, e impõe ao Reich Alemão tantas e tamanhas humilhações e cargas pecuniárias que seu resultado será a guerra seguinte. ${ }^{3}$

Poucos anos após, o frágil equilíbrio estabelecido pela Liga das Nações - que focara apenas em um dos pilares em princípio necessário para se evitar uma guerra começa a ruir. Do ponto de vista econômico, ocorre a crise de 1929, também denominada de Grande Depressão. Período iniciado com uma queda drástica das bolsas de valores de Nova Yorque, que, na sequência - mas diferentemente e em uma velocidade bem diferente

\footnotetext{
${ }^{2}$ Segundo Watson "A Guerra de 1914-1918, agora normalmente chamada de Primeira Guerra Mundial, foi na realidade uma Guerra europeia, lutada por razões europeias e alimentada por paixões europeias. (2004, p. 389.)

3 "O Acordo de Versalhes (inclusive os tratados acessórios e o estabelecimento da Liga das Nações) é frequentemente contado como o primeiro ato constituinte de auto-regulação global por parte de uma sociedade que se tornara mundial. Olhando para trás, contudo, ele parece cada vez mais um arranjo transitório. Com a ausência da Rússia e da Alemanha, o acordo foi elaborado pelas grandes potências ocidentais. Seu objetivo era produzir tanto um acerto para a Europa que pudesse funcionar, quanto a planta das regras e das instituições de uma sociedade mundial capaz de manter a ordem e evitar a guerra. Em contraste com seus antecessores, Vestfália, Utrecht e Viena, o Acordo de Versalhes teve tantos defeitos, e foi tão menos congruente com as realidades da situação, que não conseguiu atingir nenhum dos dois objetivos. Diz-se às vezes que o sofrimento torna os homens mais sábios. Isso não aconteceu na Primeira Guerra Mundial. (WATSON, 2004. P. 391-392)
} 
da crise do subprime de 2008 - atingiu fortemente países como a Alemanha, Holanda, Austrália, França, Itália, Inglaterra e Canadá. Esta quebra de Wall Street levou milhares de pessoas a perderem tudo, gerando um grande período de depressão econômica, que levou a altas taxas de desemprego, queda no produto interno bruto, queda na produção industrial e uma redução da atividade econômica em diversos pontos do globo. Esta crise tem um longo histórico que a precede (SENNHOLZ, 2010; ROTHBARD, 2013), mas como uma das consequências, acelera o inevitável avanço do nacionalismo na Europa, especialmente na Alemanha, bem como a chegada nesta do Partido Nacional Socialista dos Trabalhadores Alemães (Nationalsozialistische Deutsche Arbeiterpartei, criando com a sua abreviatura o termo Nazi, de Nacional Socialista) ao poder, e dentro deste, de Adolf Hitler, em 1933.

Um ano antes, em 1932, Huxley lança a primeira edição de Brave New World, hipotetizando o que seria uma sociedade permanentemente em paz, e o que seria efetivamente necessário para isso. Pouco mais de oitenta anos depois, parece que este, por vezes, não está tão longe da verdade que pode ser encontrada fragmentada pelo mundo atualmente internacionalizado e por vezes globalizado.

Após o fim da Segunda Guerra, também dita mundial, novo tratado de paz é estabelecido. Segundo Watson (2004, p. 401), neste momento:

[...] que se seguiu à devastação da Segunda Guerra Mundial, os vencedores defrontaram-se com duas questões de grande importância em termos da ordem mundial. A primeira era como reagir às pressões desconhecidas de um sistema reformulado que os colocava numa situação mais difícil do que antes. A segunda era que regras e instituições deveriam ser dadas à nova, e não mais eurocêntrica, sociedade internacional.

Nesta sociedade internacional, que nasce bipolar - entre os Estados Unidos da América e a União da República Socialista Soviética (URSS) - busca-se estabelecer uma estrutura formal mais robusta que uma simples Liga das Nações (WATSON, 2004).

No encontro em Bretton Woods, buscaram se estabelecer estruturas que visassem não apenas a garantia da paz mundial pela diplomacia. Em face do desencadear de consequências resultantes de uma crise econômica, verificou-se que também para esta área deveriam ser estabelecidos pilares que sustentassem um equilíbrio mundial. Assim, segundo Barral (2002, p. 12):

[...] ao término aquele encontro, houve consenso quanto à necessidade de: (a) um fundo monetário, que pudesse resguardar as economias nacionais contra crises cambiais (o FMI); (b) um banco que financiasse a reconstrução europeia e o desenvolvimento (O BIRD ou Banco Mundial); 
(c) uma organização internacional que regulamentasse os fluxos comerciais (a OIC).

Os dois primeiros efetivamente foram criados neste período. Já a OIC deu lugar ao Acordo Geral sobre Tarifas e Comércio (GATT, em inglês), cujo objetivo se fixou na redução de tarifas alfandegárias no comércio internacional (BARRAL, 2002). ${ }^{4}$ Segundo Sato (2001, p. 6):

[...] os Acordos de Bretton Woods estabeleceram as bases de uma nova ordem monetária e financeira internacional. Entretanto, a cooperação com vistas ao estabelecimento de uma instituição internacional para orientar e fomentar o desenvolvimento do comércio, apesar de ser considerada como peça fundamental desse esforço de reorganização da economia internacional como um todo, teve um destino diferente.

E, em 1994, ao final da Rodada Uruguai, o GATT, juntamente com outros $\operatorname{tratados}^{5}$, transforma-se na Organização Mundial do Comércio - OMC, que hoje abarca uma gama bem mais ampla de temas além das barreiras tarifarias.

Ao lado das instituições financeira, econômica e comercial, foi criada a Organização das Nações Unidas - ONU. Esta, com objetivo de substituir e concretizar a paz não obtida pela Liga das Nações, tem como propósito, segundo disposto no art. 1 da Carta das Nações Unidas, assinada em São Francisco a 26 de junho de 1945:

\footnotetext{
${ }^{4}$ Isso por que após os EUA terem negociado todo o sistema em Bretton Woods, o Congresso Americano não ratificou a Carta de Havana, permitindo que ficasse em seu lugar o GATT, o qual não exigia a aprovação do Congresso Nacional, mas tão somente um acordo executivo.

5 - Acordos Multilaterais de Comércio de Bens (GATT.)

Acordo Geral de Tarifas e Comércio de 1994

Acordo sobre Agricultura

Acordo sobre Aplicação de Medidas Sanitárias e Fitossanitárias

Acordo sobre Têxteis e Vestuário

Acordo sobre Barreiras Técnicas ao Comércio

Acordo sobre Medidas de Investimento Relacionadas com o Comércio

Acordo sobre a Implementação do Artigo VI do GATT 1994

Acordo sobre a Implementação do Artigo VII do GATT 1994

Acordo sobre Inspeção Pré-Embarque

Acordo sobre Regras de Origem

Acordo sobre Procedimentos para o Licenciamento de Importações

Acordo sobre Subsídios e Medidas Compensatórias

Acordo sobre Salvaguardas

- Acordo Geral sobre Comércio de Serviços e Anexos (GATS)

- Acordo sobre Aspectos dos Direitos de Propriedade Intelectual Relacionados ao Comércio (TRIPS)

- Entendimento relativo às Normas e Procedimentos sobre Solução de Controvérsias

- Mecanismo de Exame de Políticas Comerciais

- Acordos de Comércio Plurilaterais

Acordo sobre Comércio de Aeronaves civis

Acordo sobre Compras Governamentais

Acordo Internacional sobre produtos Lácteos

Acordo Internacional sobre Carne Bovina.
} 
1. Manter a paz e a segurança internacionais e, para esse fim: tomar, coletivamente, medidas efetivas para evitar ameaças à paz e reprimir os atos de agressão ou outra qualquer ruptura da paz e chegar, por meios pacíficos e de conformidade com os princípios da justiça e do direito internacional, a um ajuste ou solução das controvérsias ou situações que possam levar a uma perturbação da paz;

2. Desenvolver relações amistosas entre as nações, baseadas no respeito ao princípio de igualdade de direitos e de autodeterminação dos povos, e tomar outras medidas apropriadas ao fortalecimento da paz universal;

3. Conseguir uma cooperação internacional para resolver os problemas internacionais de caráter econômico, social, cultural ou humanitário, e para promover e estimular o respeito aos direitos humanos e às liberdades fundamentais para todos, sem distinção de raça, sexo, língua ou religião; e

4. Ser um centro destinado a harmonizar a ação das nações para a consecução desses objetivos comuns. ${ }^{6}$

Observa-se, portanto, que enquanto em Brave New Word há uma permanente organização de pessoas, seu condicionamento pessoal, genético e social, por outro lado atualmente vivemos em um condicionamento constante da sociedade, cada vez com mais organizações fragmentadas, setorizadas e especializadas a fim de que nada não seja regulado e controlado, mas com uma ótica de liberdade, de opção.

Internacionalmente, com base nos propósitos anteriormente referidos, cria-se então esta organização principal, com várias instâncias e órgãos, destinados a finalidades específicas, tais como: a Assembleia Geral da ONU, da qual toma parte todo Estado Membro da organização; a Corte Internacional de Justiça, que serve como órgão para solução de controvérsias entre as Nações; o Conselho de Segurança, composto inicialmente de onze membros, sendo cinco permanentes (China, Estado Unidos da América, França, Reino Unido e União Soviética / Rússia) com direito a veto, e outro seis eleitos pela Assembleia Geral para um período de dois anos. Em 1963 a composição foi alterada passando a ter dez membros não permanentes e mais os cinco permanentes continuando estes últimos com direito a veto. Além destes órgãos, a ONU ainda congrega organizações internacionais especializadas de vocação universal. ${ }^{7}$

\footnotetext{
${ }^{6}$ Internalizado no Brasil por meio do Decreto Presidencial n. 19.841, de 22 de outubro de 1945.

${ }^{7}$ Tais como a Organização Internacional do Trabalho (OIT), a Organização para a Alimentação e Agricultura (FAO), a Organização para a Educação, Ciência e Cultura (UNESCO), Organização Mundial da Saúde (OMS), a Organização Meteorológica Mundial (OMM), União Postal Universal (UPU), Organização Marítima Internacional (OMI), União Internacional de Telecomunicações (UIT), Organização Mundial para a Propriedade Intelectual (OMPI), Organização para o Desenvolvimento Industrial (ONUDI), Agência Internacional de Energia Atômica (AIEA) e as já citadas Organização Mundial do Comércio (OMC), Banco Mundial (BIRD) e Fundo Monetário Internacional (FMI), entre outros mais específicos. (ACCIOLY, SILVA, CASELLA, 2009, p. 420-421)
} 
Embora guerras ditas mundiais efetivamente não tenham acontecido após o estabelecimento desta nova estrutura na ordem mundial, todo o aparato criado não foi suficiente para evitar carnificinas locais e regionais. Muitas destas oriundas do movimento de descolonização que iniciou-se em países asiáticos, seguindo-se aos países africanos. Muitos povos, originalmente inimigos, que viviam sob o jugo de um Estado colonizador, repentinamente ganham uma liberdade para conviver entre si. E muitos destes ainda, ficaram sob os auspícios de uma velada batalha mundial, a denominada Guerra Fria, que angariava aliados em todos os confins do planeta terra.

Embora a guerra fria tenha, de certa forma, terminado com a "queda do muro de Berlin” em 1989, pausando a bipolaridade com que finalizou-se a segunda guerra, novas polaridades se apresentam neste momento, como as religiosas, econômicas, ambientais, etc.

E aqueles países, que haviam sido "adotados" pelo lado socialista, também entram em conflitos internos após deste conflito, posto que se veem isolados, sem recursos externos, e antigos conflitos e diferenças internas começam a aflorar.

Há um mundo em combustão, embora não haja uma guerra mundial. O que há é um mundo sem dono e sem comando, ou muitos comandos e pretensos donos para pouco espaço e pessoas que querem sua liberdade?

No novo mundo de Huxley não haveria espaços para guerras, nem locais, nem regionais, inimagináveis globais. Eventualmente poderia haver como cita o autor, experiências isoladas em ilhas, objetivando o estudo do comportamento de determinadas castas - no caso específico verificou-se que os Alfas não foram criados para viverem sem os demais e eles mesmos (aqueles que sobraram) solicitaram voltar para o mundo "normal" (HUXLEY, 2009).

Isso porque haveria apenas uma ordem, um comando, um sistema. Sem questionamentos, sem diversidade de opiniões. Apenas pessoas vivendo segundo a ordem pré-estabelecida para suas criações. Viajando a todos os continentes, onde encontrariam exatamente o mesmo sistema, com o mesmo comando e a mesma ordem. Sem nenhum foco de revolta, e eliminando-se qualquer possível foco, não há revolta. Eliminando qualquer questionamento, não há questionamento. Sem isso, tudo continua exatamente como está. 
Mas não seria esta a Paz Perpétua elaborada nos postulados de Kant (2004), pois nestes ainda havia vontades, que necessitavam ser conjugadas para que a paz fosse garantida. Quando não há vontades, há paz?

\section{2 - A utopia da tecnologia}

O livro, que ora se torna protagonista deste ensaio, nasce entre as duas grandes guerras. Buscaria ele retratar uma paz apenas mundial, ou também abarcaria ele a paz regional e local?

A história inicia-se em 632 d.F. ou seja, 632 depois do nascimento de Henry Ford. Por que um marco da tecnologia substituindo a religião, que neste período deste novo mundo já nem sabe-se o que é?

A estabilidade mundial desta nova era está instalada sobre uma das grandes utopias: a utopia tecnológica. Há mecanismos para resolução de todos os problemas, compreendendo-se na menção tecnologia as inovações trazidas de todos os campos da ciência que se tornaram aplicáveis. Neste sentido se abarca tecnologias relacionadas com a química, a física e a biologia, desde a criação do soma à mutação e manipulação genética em todos os sentidos dos seres que são representados no novo mundo - alfas, betas, gamas, etc.

Esta mesma utopia também se apresenta no livro Eu, Robo, de Isaac Asimov, lançado em 1950, o qual inspira o filme de mesmo nome. Neste, o autor trabalha na utopia tecnológica da construção de um sistema de inteligência artificial implementado em um robô perfeito, que seguiria as três regras da robótica:

$1^{a}$ Lei: Um robô não pode ferir um ser humano ou, por inação, permitir que um ser humano sofra algum mal.

$2^{\mathrm{a}}$ Lei: Um robô deve obedecer as ordens que lhe sejam dadas por seres humanos exceto nos casos em que tais ordens entrem em conflito com a Primeira Lei.

$3^{\mathrm{a}}$ Lei: Um robô deve proteger sua própria existência desde que tal proteção não entre em conflito com a Primeira ou Segunda Leis.

O objetivo desta tecnologia é proteger o ser humano, mas esta lógica perfeita leva à seguinte dedução: se Eu, Robô, preciso proteger os humanos e eles podem fazer mal 
a si mesmos e aos demais, a melhor forma de protege-los é retirando-lhes a liberdade e vigiando-os 24 horas por dia, assim, eles não poderão fazer mal a outros seres humanos nem a si mesmos.

Sua similitude com o que ocorre com o livro é muito grande, mas neste admirável mundo novo a tecnologia age de forma mais sutil, pois é controlada por humanos. A lógica deste novo mundo, que surge após uma sangrenta guerra, é proteger os seres humanos. Para tanto, uma das opções aventadas é tirar-lhes a liberdade sem que eles percebam e vigiá-los sem que eles estranhem.

A liberdade destes habitantes é retirada desde antes do berço, na sua configuração genética, quando, por meio desta, define-se a casta a qual irão pertencer e o que farão para o resto de suas vidas. Aliás, a própria forma de procriar é um cerceamento da liberdade, posto que a ninguém mais é dado o direito de ter filhos, a ponto da palavra "mãe" ser considerado uma expressão inaceitável. Eles deixam de ser bípedes.

Após o nascimento, cada uma das castas é submetida durante toda a sua infância ao condicionamento necessário para que esta atue onde deve, durante a vida adulta. Sem duvidar, com técnicas de condicionamento que tornam naturais a discriminação entre castas e a opção por modos de vidas totalmente distintos.

Os momentos de angústia são limitados pelo uso de uma droga sem efeitos colaterais físicos: o soma. Assim, até a liberdade de entristecer-se é retirada, a liberdade de chorar, de deprimir-se é substituída por um direito absoluto a um padrão de felicidade tranquila e que não cause danos ao sistema.

Há liberdade para os excessos, especialmente para o sexo e para os gastos, pois nenhuma vontade pode ser reprimida, para que não surjam novas vontades. Mas não há liberdade para se escolher apenas uma pessoa para se passar o restante da vida. A liberdade que existe é para seguir-se o padrão, sempre, nunca para questioná-lo, como em qualquer ditadura, qualquer regime autoritário, com a diferença de que ninguém entende quando alguém questiona este regime. E os questionadores são mandados para uma ilha distante, para que esta "doença" não contamine a sociedade.

E para complementar a falta de liberdade, ocorre a vigilância. Não vigilância na forma preconizada em "1984" por George Orwell, publicado em 1948 - logo após a segunda grande guerra e transformado em filme em 1984. Mas aquela que é exercida por todos, fruto do condicionamento e do bem estar superficial que embala esta sociedade. 
Durante o dia todos trabalham, todos estão juntos o tempo todo e devem agir como "adultos". E, à noite, não se pode ir para casa, estar sozinho. Deve-se sair, para divertir-se, encontrar alguém e aproveitar a noite, a vida e assim todas as noites, como "crianças", pois todos foram condicionados a estar o tempo todo em sociedade, e a consumir o soma quando isso momentaneamente não parecesse suportável. Mesmo o não consumo desta droga é vigiado pelos colegas, comentado com os superiores, assim como não sair com alguém, não participar dos jogos, nem das orgias, não ser "normal".

Todavia, ao contrário de "Eu, robô", não há um momento em que todos os humanos começam a questionar o sistema e este tende a implodir. Neste "Admirável Mundo Novo", quem nasce dentro do sistema e o questiona, como ocorre no caso do Dr. Bernard Marx, é convidado, junto com seu colega Helmholtz Watson, a retirar-se do seio desta sociedade, sendo estes encaminhados às ilhas Falkland, por um dos dez Administradores do planeta, Mustafá Mond.

Já o Selvagem, que nasce fora deste sistema e, ao entrar nele, o questiona, acaba por ser engolido pelo sistema, destruído, a partir do momento que os seus valores o são. Uma sociedade condicionada não suporta valores diferentes. A mídia não suporta padrões diferentes. E os poucos lúcidos ou fingem-se de loucos ou enlouquecem.

O que se confirma, em qualquer dos casos, é a necessidade de vigilância e supressão da liberdade e da vontade, para que se garanta esta estabilidade. Não se trata de paz, mas de uma constante estabilidade. Mas... a tecnologia, com toda a sua evolução, só poderá ser efetivamente aperfeiçoada pelo ser imperfeito que faz uso dela: o homem.

Para isso, neste mesmo mundo, devem existir estes administradores, e possivelmente estas ilhas com pessoas que pensam. Pois a própria tecnologia, para que se mantenha e cumpra sua função, precisa estar em constante aperfeiçoamento. E quem a aperfeiçoa precisa conhecer além do que aqueles que estão submetidos a esta vigilância e cerceamento de vontade e liberdade.

Interessante é imaginar até quando esta estabilidade pode durar.

Pois, se é possível manipular os genes, alterar seu desenvolvimento, condicionar a infância, sabe-se que dentro de cada corpo há algo que é único - seja isso chamado de espírito ou alma, seja isso considerado imortal ou não. 
Todavia, embora Huxley não trate disso, e sua mensagem seja de uma estabilidade eterna, que não poderá ser quebrada - portanto uma nova ordem definitiva -, é possível pensar nos grandes épicos, nas epopeias, nos heróis, e imaginar que, embora todos os corpos sejam programados da mesma forma, há algo que os habita que é diferente. E é este diferencial que poderá mudar o curso da história deste novo mundo, criado para ser perfeito. O Dr. Bernard Marx é um exemplo desta quebra de padrão, é um indício disso e também um exemplo de como se lida com isso (HUXLEY, 2009).

No filme A Ilha, de 2005, dirigido por Michael Bay, também havia uma manipulação genética, com um fim específico. Neste filme, que se passaria em 2019 e retrataria um grande complexo dos EUA onde todos os moradores seriam os únicos sobreviventes a um ataque de um vírus mortal que dizimou a terra, o único lugar no planeta onde esse vírus não chega é um lugar paradisíaco chamado de A Ilha, e periodicamente um dos moradores deste complexo eram sorteados para ir a este local como prêmio. Criados adultos, em um mundo a parte, sob um condicionamento, tudo parece perfeito para o propósito almejado. Mas algo fez com que alguns destes moradores desconfie que algo não está de acordo.

Na trilogia The Matrix, de 1999 a 2013, dirigido pelos irmãos Wachoswki, toda a humanidade vive conectada a um programa de computador, que simula uma realidade, enquanto seus corpos são utilizados como fonte de energia aos robôs que dominaram o planeta Terra. Neste também há, em alguns, a desconfiança de que algo é diferente do que realmente aparenta. E é com base nisso que o protagonista Neo é convidado a conhecer a realidade.

São apenas exemplos de alguns filmes, mas há inúmeras obras que têm como ponto de partida ou inspiração o Admirável Mundo Novo retratado por Huxley. Todos, porém, imaginam um fim diferente para a humanidade, pois certamente o que se vê em Huxley é sombrio de mais para ser aceitável.

\section{Considerações finais: a tecnologia é neutra, a paz não.}

A título de considerações finais, retomando o questionamento inicial, perguntase se poderia haver uma paz perpétua, permanente, imutável. Seria o custo dela o retratado no Admirável Mundo Novo? 
O primeiro ponto a ponderar é considerar que o ser humano não é perpétuo, permanente, imutável. Portanto, esta paz também não o seria, mas dinâmica, adaptada e adaptável ao próprio ser humano. Trata-se de uma opção, a ser tomada a cada dia, e não de um estado de natureza.

Poderia a tecnologia ser utilizada para garantir a paz? Quem sabe poderia ser concebida para constantemente ser um auxiliar na sua construção, e não um protagonista.

Particularmente esta autora compreende que a humanidade encontra-se em um constante e ininterrupto estado de evolução. Apesar das guerras, das catástrofes, dos flagelos, o resultado final é uma busca pessoal e coletiva pela evolução, que compreende a paz. Se por vezes, aparentemente, há retrocessos, ao longo dos tempos o que se vê é um avanço. A humanidade já saiu de um período de barbárie, a tortura e as penas cruéis ou degradantes já não são mais aceitas uniformemente. Há mais pessoas com acesso a alimentos. A expectativa de vida de maneira geral tem aumentado.

Todavia, essas pequenas grandes evoluções somente são possíveis junto a povos que disponham de liberdade, que possam expressar sua vontade, mesmo que isso por vezes possa levar a revoluções, a rupturas radicais que permitam novos recomeços. A guerra é o pior dos mundos, o gesto mais degradante que pode exercer o ser humano ao tirar a vida de um semelhante. Mas sem revoltas e revoluções, sem a possibilidade de lutar, o humano como ser não teria evoluído, não teria alcançado e conquistado determinados direitos inimagináveis a poucos séculos passados.

Talvez uma paz perpétua conforme a descrita no Admirável Mundo Novo mais estabilidade que paz - não seja possível, mas sim uma permanente busca da evolução do ser humano.

\section{Referências}

1984. Direção: Michael Radford. Reino Unido: Virign Films, 1984. 113 min. Som (inglês), color.

ACCIOLY, H.; SILVA, G. E. DO N.; CASELLA, P. B. Manual de Direito Internacional Público. 17 ed. São Paulo: Saraiva, 2009. 916 p.

BARRAL, W. De Bretton Woods a Doha. BARRAL, W. (org.) O Brasil e a OMC. Curitiba: Juruá, 2002. P 9-26. 
DERRIDA, J. O direito à filosofia do ponto de vista cosmopolítico. J. Guisnsburg (org.). A paz perpétua: um projeto para hoje. São Paulo: Perspectiva, 2004. p .11-29.

GENTILI, A. O direito da guerra. Ijuí: Unijuí, 2005. 628 p.

HUXLEY, A. Admirável mundo novo. São Paulo: Globo, 2009. 398 p.

I, ROBOT (Eu, Robo). Direção: Alex Proyas. Alemanha / Estados Unidos da América: Fox Searchlight Pictures, 2004. 114 min. Som (inglês), color.

KANT. I. Para a paz perpétua. J. Guisnsburg (org.). A paz perpétua: um projeto para hoje. São Paulo: Perspectiva, 2004. p .31-87.

ORWELL, George. 1984. São Paulo: Companhia das Letras, 2009. 416 p.

ROTHBARD, M. N. O que causou a grande depressão do século XIV. 31 de dezembro de 2013. Disponível em: http://www.mises.org.br/Article.aspx?id=1091. Acesso em: 20 jun 2014.

SATO. E. Mudanças estruturais no sistema internacional: a evolução do regime de comércio do fracasso da OIC à OMC. Maio 2001. Disponível em: http: // cedep.ifich.ufrgs.br/T Alberico Gentili extos_Elet/pdf. Acesso em: 20 jun 2014.

SENNHOLZ, H. F. A Grande Depressão - uma análise das causas e consequências. 21 de junho de 2010. Disponível em: http://www.mises.org.br/Article.aspx?id=376 Acesso em: 20 jun 2014.

THE ISLAND (A Ilha). Direção: Michael Bay. Estados Unidos da América: Warner Bros, 2005. 127 min. Som (inglês), color.

THE MATRIX RELOADED. Direção: Andrew Paul "Andy" Wachowski e Lana Wachowski. Estados Unidos da América / Austrália: Warner Bros, 2003. 138 min. Som (inglês), color.

THE MATRIX REVOLUTIONS. Direção: Andrew Paul "Andy" Wachowski e Lana Wachowski. Estados Unidos da América / Austrália: Warner Bros, 2003. 129 min. Som (inglês), color.

THE MATRIX. Direção: Andrew Paul "Andy" Wachowski e Lana Wachowski. Estados Unidos da América / Austrália: Warner Bros, 1999. 136 min. Som (inglês), color. 
WATSON, A. A evolução da sociedade internacional: uma análise histórica comparativa.

Brasília: UNB. 2004. 476 p.

(Artigo submetido em 23/06/2014 e aceito em 14/07/2014) 